\title{
A prognostic nomogram for event-free survival in patients with atrial fibrillation before cardiac resynchronization therapy
}

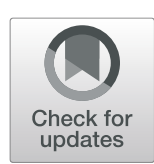

Minsi Cai, Wei Hua* ${ }^{*}$, Nixiao Zhang, Shengwen Yang, Yiran Hu, Min Gu, Hongxia Niu and Shu Zhang

\begin{abstract}
Background: Atrial fibrillation (AF), one of the most common comorbidities of heart failure (HF), is associated with worse long-term prognosis in HF patients receiving cardiac resynchronization therapy (CRT). However, there is still no convenient tool to identify CRT candidates with AF who are at high risk of mortality and hospitalization due to HF.

Methods: We included 152 consecutive patients with AF for CRT in our hospital from January 2009 to July 2019. Multiple imputation was used for missing values. With imputed datasets, a multivariate Cox regression model was performed for variable selection using the backward stepwise method to predict all-cause mortality and HF readmissions. A nomogram and nomogram-based scoring system were constructed from the selected predictors. Then, internal validation and calibration were achieved by the bootstrap method, deriving the corrected concordance index and calibration curves. Sensitivity analysis was also performed to validate our selected predictors.
\end{abstract}

Results: Five predictors were incorporated in the nomogram, including N-terminal pro brain natriuretic protein (NTproBNP) $>1745 \mathrm{pg} / \mathrm{mL}$, history of syncope, previous pulmonary hypertension, moderate or severe tricuspid regurgitation, thyroid-stimulating hormone (TSH) $>4 \mathrm{mIU} / \mathrm{L}$. The concordance index $(0.70,95 \% \mathrm{Cl} 0.62-0.77)$, corrected concordance index $(0.67,95 \% \mathrm{Cl} 0.59-0.74)$ and calibration curve showed optimal discrimination and calibration of the established nomogram. A significant difference in overall event-free survival was recognized by the nomogram-derived scores for patients with high risk ( $>50$ points), intermediate risk (21-50 points) and low risk (0-20 points) before CRT.

Conclusion: Our internally validated nomogram may be an applicable tool for the early risk stratification of CRT candidates with AF.

Keywords: Atrial fibrillation, Cardiac resynchronization therapy, Heart failure, Nomogram

\section{Background}

Cardiac resynchronization therapy (CRT) improves cardiac function and reduces morbidity and mortality in appropriately selected heart failure (HF) patients with sinus rhythm via biventricular pacing (BIVP) [1-3].

\footnotetext{
* Correspondence: drhuaweifw@sina.com

Chinese Academy of Medical Sciences \& Peking Union Medical College

Fuwai Hospital, No. 167, Beilishi Rd, Xicheng District, Beijing 100037, China
}

However, the efficacy of CRT in patients with atrial fibrillation (AF) still remains a knowledge gap, although the concurrence of $\mathrm{AF}$ and $\mathrm{HF}$ is common in clinical practice, ranging from $<5 \%$ in asymptomatic HF patients to nearly $50 \%$ in symptomatic HF patients [4]. Several studies have supported the benefits of CRT in AF patients [5-8], though compared with those in sinus rhythm, AF was also associated with a higher risk of

C C The Author(s). 2020 Open Access This article is licensed under a Creative Commons Attribution 4.0 International License, which permits use, sharing, adaptation, distribution and reproduction in any medium or format, as long as you give appropriate credit to the original author(s) and the source, provide a link to the Creative Commons licence, and indicate if changes were made. The images or other third party material in this article are included in the article's Creative Commons licence, unless indicated otherwise in a credit line to the material. If material is not included in the article's Creative Commons licence and your intended use is not permitted by statutory regulation or exceeds the permitted use, you will need to obtain permission directly from the copyright holder. To view a copy of this licence, visit http://creativecommons.org/licenses/by/4.0/ The Creative Commons Public Domain Dedication waiver (http://creativecommons.org/publicdomain/zero/1.0/) applies to the data made available in this article, unless otherwise stated in a credit line to the data. 
mortality in CRT candidates [9-11]. Unfortunately, there are currently no predictive models proposed in clinical practice for AF patients undergoing CRT that can stratify patients by risk and evaluate their long-term prognosis. Therefore, we aimed to construct an easy-to-use nomogram to satisfy this urgent need. The nomogram incorporates baseline features before CRT as predictors and is effective for risk stratification among AF-HF patients.

\section{Methods}

\section{Study design and population}

We collected the medical records of all AF patients who underwent successful CRT or CRT-ICD (CRTD) for the first time at Fuwai Hospital between January 2009 and July 2019. AF subtypes were diagnosed according to criteria in the guidelines [12].

Patients who met the following criteria were included in the study: (1) without atrioventricular junction ablation (AVJA) before CRT/CRT-D or during follow-up; (2) without a history of successful radiofrequency ablation for atrial arrhythmia before CRT/CRT-D or during follow-up; and (3) with complete survival data. Finally, 152 patients were eligible for the data analysis (Online Fig. S1).

All patients received CRT implantation according to the guidelines [1, 13, 14]. Left ventricular (LV) pacing leads were preferably implanted in posterior-lateral, anteriorlateral or lateral veins through the coronary sinus. If implanting LV leads was not possible or failed, epicardial pacing would be the next choice. A successful CRT would entail the following: (1) all leads were fixed firmly at the target locations (right ventricular [RV] lead preferably at the apex; LV lead preferably in posterior/anterior lateral veins; atrial lead preferably at the right auricle but may not be implanted in permanent AF); (2) RV/LV lead with a pacing threshold $\leq 3.5 \mathrm{~V} / 0.4 \mathrm{~ms}$ and atrial lead $\leq 1.5 \mathrm{~V} / 0.4 \mathrm{~ms}$; and (3) sensing and lead impedance in normal range defined by different pacemaker manufacturers. After implantation, parameter optimization on CRT was performed to achieve the shortest QRS duration for each individual patient. All patients were given individualized drug treatment at the discretion of doctors and clinical guidelines after discharge $[1,13,14]$. Follow-up was conventionally performed at 1,3 , 6 and 12 months after implantation during the first year and every 12 months subsequently. If there is a need or emergency, follow-up might be possible at any time. During each visit, the devices were interrogated: an experienced cardiologist and a technician of the pacemaker manufacturer checked basic parameters (sensing, lead impedance, threshold, etc.) and warnings on the programmer; pseudofusion would be identified by comparing QRS morphology and the location of the spike during each interrogation. Echocardiography and laboratory tests might be given, and VVI pacing mode, mode switch function or drug optimization would be initiated if necessary.

\section{Study endpoints}

Patients with hospitalization due to heart failure (HFH) were defined as those with typical symptoms of heart failure (including paroxysmal nocturnal dyspnea, orthopnea, edema, faint or dizzy feelings, palpitation, etc.) who were presented to the hospital and stayed over $24 \mathrm{~h}$, receiving at least 1 intravenous treatment (diuretics, inotropes, amiodarone, etc.) [15]. A composite endpoint was defined as the combination of all-cause mortality and $\mathrm{HFH}$. Patients undergoing heart transplantation and left ventricular assist device implantation were defined as cardiovascular death.

\section{Data collection}

The previous history and diagnosis, examination data and laboratory tests of all patients during hospitalization were obtained from the Electronic Medical Record System (EMRS) of Fuwai Hospital, including thyroid function test, liver and renal function test, electrolyte examination, NT-proBNP test, chest X-ray, echocardiography and electrocardiography.

Survival data, including hospitalization due to heart failure, causes of death and date for the endpoints, were retrieved not only from each follow-up and the EMRS, but also from contact with patients or their relatives via telephone or communication software.

All of the data were reviewed by two authors (MS, Cai and $\mathrm{YR}, \mathrm{Hu}$ ). Written informed consent was obtained before implantation and the study was approved by the ethics committee of Fuwai Hospital and adhered to the Declaration of Helsinki.

\section{Statistical analysis}

Data analysis was performed in $\mathrm{R}$ version 3.6.0. Potential variables for model construction were based on a clinical priori and the findings of previous studies: age, sex, cardiac function class (NYHA class), AF type, complete left bundle branch block (CLBBB), complete right bundle branch block (CRBBB), intraventricular block (IVB), frequent premature ventricular contraction (fPVC, defined as an average of 10 or more PVCs per hour while monitored [16]), history of syncope, history of pulmonary hypertension, dilated cardiomyopathy (DCM), diabetes, coronary heart disease, pre-implantation echography parameters (including LVEF, mitral regurgitation (MR) and tricuspid regurgitation (TR)), creatinine, blood urea nitrogen (BUN),estimated glomerular filtration rate (eGFR), TSH, NT-proBNP, QRS duration (QRSd), cardiothoracic ratio and pulmonary congestion in $\mathrm{X}$ ray $[9$, 10, 17-22]. Continuous variables were described as the mean with standard deviation (SD) or median with interquartile range (IQR). Most of them were categorized based on conventional cutoff values in clinical practice (for example, $4 \mathrm{mIU} / \mathrm{L}$ for TSH) except for NT-proBNP, 
which was dichotomized based on maximally selected rank statistics [23]. Categorical variables were summarized as frequencies (\%). Univariate Cox proportional hazards regression and $\mathrm{K}-\mathrm{M}$ plot were used to find associations between variables and event-free survival. Variables included in multivariate Cox regression for further selection were those with a statistical significance of $P<$ 0.2 or with clinical importance.

In terms of the Cox multivariate model, missing values were replaced by multiple imputation and then, predictor selection using backward stepwise regression with Akaike information criterion (AIC) on all imputed datasets was conducted. Final predictors would be variables remaining in nearly or over half of the models [24]. The proportional hypothesis was validated for the final model. Multicollinearity was evaluated by the variance inflation factor (VIF).

A nomogram based on the results of multivariate analysis was built with the rms package. The concordance index (Cindex) was used to evaluate the discrimination ability of the nomogram, and calibration curves were used to assess the difference between the actual and predicted event-free survival rates using bootstrapping (500 resamplings) [25]. Internal validation was performed using bootstrapping (1000 resamplings) to avoid potential overfitting, and then a corrected C-index was given, which showed the future performance of our multivariate model for extrapolation. A risk scoring system based on the nomogram was constructed, and the total points of all patients were calculated. Patients were allocated to 7 groups according to their different scores, and subgroups with similar trends of eventfree survival were merged.

Sensitivity analysis was performed in the following two ways. (1) An additional multivariate Cox model derived from complete cases (subjects without missing values for the selected predictors) in the same way as previously mentioned was used to validate the predictors in our nomogram. (2) TSH levels of patients with or without amiodarone intake were compared by the MannWhitney $\mathrm{U}$ test. A K-M plot was used to determine whether TSH still served as a predictor of survival in patients without amiodarone use. Finally, a multivariate predictive model was derived from complete cases without amiodarone intake. All of the above were used to rule out the influence of amiodarone on TSH levels. A comparison between the nomogram and a single predictor was performed to assess predictive accuracy.

\section{Results}

\section{Baseline characteristics}

One hundred and fifty-two patients were included in the analysis. The median age was 62 years (interquartile range (IQR), 54-69 years), and 41 patients were female (27\%). Persistent or permanent atrial fibrillation was seen in 70 patients (46.1\%), and paroxysmal atrial fibrillation was seen in 82 patients (53.9\%). The median QRS duration before implantation was $160 \mathrm{~ms}$ (IQR, 144-176.5 ms) with a median LVEF of 31.5\% (IQR, 26$38 \%$ ) and CLBBB in $53.3 \%$ of patients. Additionally, moderate or severe TR was present in 40 patients (26.3\%), and pulmonary hypertension diagnosed before implantation was present in 29 patients (19.1\%). A history of syncope was reported in 33 individuals (21.7\%). With regard to laboratory tests, the median concentration of NT-proBNP was $1702 \mathrm{pg} / \mathrm{mL}$ (IQR, 1009.1-2612 $\mathrm{pg} / \mathrm{mL}$ ) and TSH was $2.32 \mathrm{mIU} / \mathrm{L}$ (IQR, 1.44-4.25 mIU/ L). Other characteristics were also shown in Table 1.

\section{Treatment and survival}

During hospitalization and after discharge, the patients were given individualized drug treatments, including ACEI/ ARB $(n=117,77 \%)$, beta-receptor blockers $(n=128$, $84.2 \%)$, spironolactone $(n=124,81.6 \%)$, digitoxin $(n=80$, $50.2 \%)$, diuretics $(n=139,91.4 \%)$, statins $(n=70,46.1 \%)$, amiodarone $(n=47,30.9 \%)$, antiplatelets $(n=37,24.3 \%)$, warfarin $(n=32,21.1 \%)$ and NOAC $(n=30,19.7 \%)$.

The median follow-up was 578.5 days (range, 9-3888 days). During this period, 28 patients died (18.4\%), 18 from cardiovascular causes (11.8\%) and 10 from unexplained causes or other diseases (6.6\%); 49 experienced HFH (32.2\%), which resulted in 56 in total reaching the composite endpoint (36.8\%). The event-free survival was 82,73 and $44 \%$ at the 1-, 2- and 5-year follow ups, respectively (Fig. 1).

\section{Predictors and nomogram construction}

Five predictors were selected in a final model: preimplantation NT-proBNP > $1745 \mathrm{pg} / \mathrm{mL}$ (hazard ratio (HR) 2.47, 95\% confidence interval (CI) 1.35-4.49, $P=0.0031)$, moderate/severe TR (HR 1.50, 95\% CI 0.82-2.73, $P=0.1857$ ), TSH $>4$ $\mathrm{mIU} / \mathrm{L}$ (HR 1.47, 95\% CI 0.79-2.73, $P=0.2204$ ), previous pulmonary hypertension (HR 1.84, 95\% CI 0.98-3.48, $P=$ 0.0595 ) and history of syncope (HR 0.64, 95\% CI 0.32-1.27, $P=0.1993)$. The proportional hazard ratio hypothesis was ensured with no signs of multicollinearity judged by VIF $<2$. Those predictors split the population into two groups with significant differences in event-free survival, except for a history of syncope with a marginal $P$ value (Table 2, Fig. 2a-e). Then a nomogram was created according to the final multivariate Cox regression model (Fig. 3).

\section{Performance of the nomogram}

The C-index of the established nomogram was 0.70 with a 95\% CI of 0.62-0.77. Furthermore, calibration curves showed a moderate correlation between the predicted event-free survival and actual survival rates at the 1-, 2and 5-year follow-ups (Fig. 4a-c). Regarding internal validation, the corrected C-index was 0.67 with a $95 \% \mathrm{CI}$ of $0.59-0.74$. 
Table 1 Baseline characteristics

\begin{tabular}{|c|c|}
\hline Baseline & Value \\
\hline \multicolumn{2}{|l|}{ Demographic characteristics } \\
\hline Age (years, median [IQR]) & $62.00[54.00,69.00]$ \\
\hline Female (\%) & $41(27.0)$ \\
\hline \multicolumn{2}{|l|}{ Operation-related characteristics } \\
\hline CRT-D implantation (\%) & $83(54.6)$ \\
\hline Lateral/anterior-lateral/posterior-lateral LV lead (\%) & $119(78.8)$ \\
\hline Upgradation from PM/ICD (\%) & $17(11.2)$ \\
\hline \multicolumn{2}{|l|}{ Comorbidities and disease history } \\
\hline Persistent/permanent AF (\%) & $70(46.1)$ \\
\hline DCM (\%) & $97(63.8)$ \\
\hline CLBBB (\%) & $81(53.3)$ \\
\hline IVB (\%) & $24(15.8)$ \\
\hline Coronary heart disease (\%) & $39(25.7)$ \\
\hline Myocardial infarction (\%) & $27(17.8)$ \\
\hline Hypertension (\%) & $52(34.2)$ \\
\hline Diabetes (\%) & $42(27.6)$ \\
\hline Hyperlipidemia (\%) & $50(32.9)$ \\
\hline NYHA III/IV (\%) & $110(72.4)$ \\
\hline AVB (\%) & $35(23.0)$ \\
\hline fPVC (\%) & $26(17.1)$ \\
\hline History of pulmonary hypertension (\%) & $29(19.1)$ \\
\hline History of PCI (\%) & $10(6.6)$ \\
\hline History of stroke (\%) & $20(13.2)$ \\
\hline History of CABG (\%) & $6(3.9)$ \\
\hline History of VTNF (\%) & $60(39.5)$ \\
\hline History of syncope (\%) & $33(21.7)$ \\
\hline \multicolumn{2}{|l|}{ Drug treatment } \\
\hline ACEI/ARB (\%) & $117(77.0)$ \\
\hline Beta receptor blockers (\%) & $128(84.2)$ \\
\hline Spironolactone (\%) & $124(81.6)$ \\
\hline Digitoxin (\%) & $80(52.6)$ \\
\hline Diuretics (\%) & $139(91.4)$ \\
\hline Statins (\%) & $70(46.1)$ \\
\hline Amiodarone (\%) & $47(30.9)$ \\
\hline Antiplatelets (\%) & $37(24.3)$ \\
\hline Warfarin (\%) & $32(21.1)$ \\
\hline $\operatorname{NOAC}(\%)$ & $30(19.7)$ \\
\hline \multicolumn{2}{|l|}{ ECG } \\
\hline Preimplantation QRSd (ms, median [IQR]) & $160.00[144.00,176.50](n=144)$ \\
\hline Postimplantation QRSd (ms, median [IQR]) & $144.00[133.50,160.00](n=143)$ \\
\hline \multicolumn{2}{|l|}{ Preimplantation chest $\mathrm{X}$ ray } \\
\hline Cardiothoracic ratio (median [IQR]) & $0.58[0.55,0.63]$ \\
\hline Pulmonary congestion (\%) & 89 (58.6) \\
\hline
\end{tabular}

Preimplantation echocardiography 
Table 1 Baseline characteristics (Continued)

\begin{tabular}{ll}
\hline Baseline & Value \\
\hline LVEF (\%, median [IQR]) & $31.50[26.00,38.00]$ \\
LVEDD (mm, median [IQR]) & $66.00[60.00,76.00]$ \\
Moderate/severe MR (\%) & $76(50.0)$ \\
Moderate/severe TR (\%) & $40(26.3)$ \\
Preimplantation laboratory tests & $1702.00[1009.10,2612.00](n=149)$ \\
NT-proBNP (pg/mL, median [IQR]) & $18.95[13.77,24.84](n=142)$ \\
Total bilirubin (umol/L, median [IQR]) & $93.30[79.28,112.20](n=151)$ \\
Creatinine (umol/L, median [IQR]) & $7.58[6.26,9.57](n=151)$ \\
BUN (mmol/L, median [IQR]) & $65.96[51.60,81.95](n=151)$ \\
eGFR (mL/min/1.73m $\left.{ }^{2}[\mathrm{IQR}]\right)$ & $2.32[1.44,4.25](n=139)$ \\
TSH (mIU/L, median [IQR]) & $98.65[95.00,99.00](n=132)$ \\
PM interrogation at last follow-up & $99[96.25,99.00](n=70)$ \\
BIVP (\%, median [IQR]) & $98[92.25,99.00](n=62)$ \\
• Paroxysmal AF & $99[97.20,99.00](n=24)$ \\
• Persistent/permanent AF & $35[30,45](n=122)$ \\
• fPVC &
\end{tabular}

$A C E l$ angiotensin-converting enzyme inhibitor, $A R B$ angiotensin II receptor blocker, $A V B$ atrioventricular block, $B I V P$ biventricular pacing, $C R T-D$ cardiac resynchronization therapy with defibrillator, $C A B G$ coronary artery bypass grafting, ICD intracardiac defibrillator, $L V E D D$ left ventricular end diastolic diameter, $N O A C$ non-vitamin $\mathrm{K}$ antagonist oral anticoagulants, $P M$ pacemaker, $P C I$ percutaneous coronary intervention, $V T$ ventricular tachycardia, $V F$ ventricular fibrillation

\section{Risk stratification of patients}

The total points of each patient were calculated from the nomogram-derived scoring system (Table 2). Subjects with different points were assigned to 7 subgroups (points: $0-10,11-20,21-30,31-40,41-50,51-60$, > $60)$, and those with similar event-free survival curves were merged (Online Fig. S2). Therefore, this population was divided into 3 groups with different risks of the composite endpoints, of which patients with $>50$ points

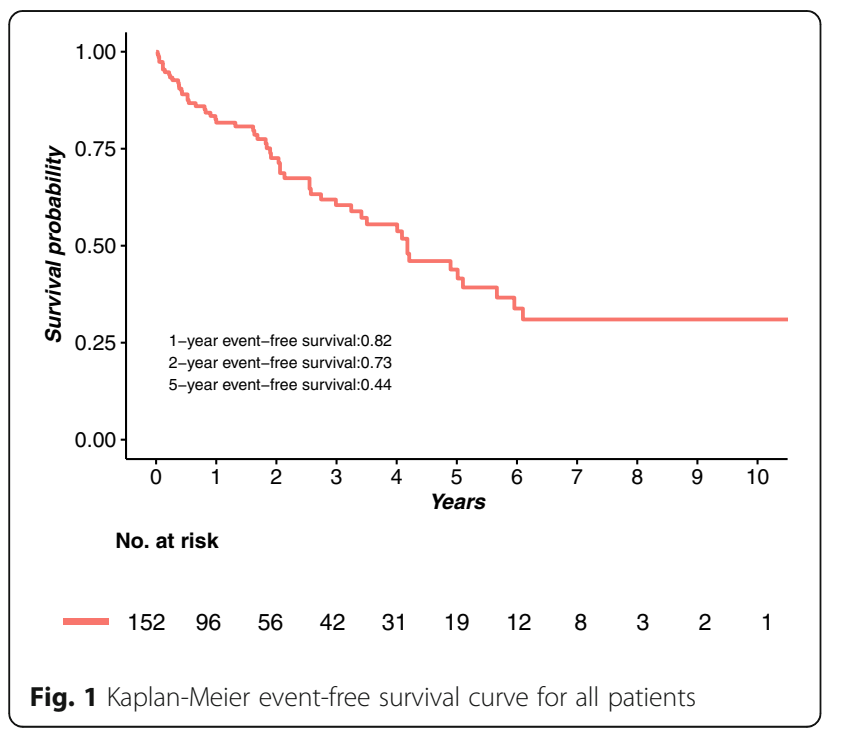

were defined as high risk, $21-50$ points as intermediate risk and $0-20$ points as low risk (Fig. $2 \mathrm{f}$ ).

\section{Alternative model based on complete cases}

A new model based on complete cases was also created (Table 2) and CLBBB (HR 0.56, 95\% CI 0.31-1.01), NTproBNP > $1745 \mathrm{pg} / \mathrm{mL}$ (HR 2.32, 95\% CI 1.23-4.38), moderate/severe TR (HR 2.02, 95\% CI 1.07-3.80) and TSH > 4 $\mathrm{mIU} / \mathrm{L}$ (HR 1.89, 95\% CI 1.03-3.46) were included. The C-index was 0.70 with a $95 \% \mathrm{CI}$ of $0.61-0.78$, and the corrected C-index was 0.67 with a $95 \% \mathrm{CI}$ of $0.60-0.75$ after internal validation. Calibration curves at 1,2 and 5 years after implantation demonstrated inferior agreement between the prediction and actual survival compared with the nomogram prediction (Fig. 4d; Online Fig. S3).

\section{The influence of amiodarone on TSH level}

Considering the possible influences of amiodarone on TSH levels, the TSH concentration of patients with and without amiodarone use were compared, but no statistical significance was found $(2.69[1.57,3.80] \mathrm{mIU} / \mathrm{L}$ vs $2.27[1.42,4.28] \mathrm{mIU} / \mathrm{L}, P=0.853)$. After patients receiving amiodarone were excluded, $\mathrm{TSH}>4 \mathrm{mIU} / \mathrm{L}$ was still a predictor for event-free survival (Online Fig. S4). Finally, the significant multivariate model based on complete cases without using amiodarone also included $\mathrm{TSH}>4 \mathrm{mIU} / \mathrm{L}$ as a predictor, with a $P$ value equal to 0.0952 . 
Table 2 Univariate and multivariate analyses

\begin{tabular}{|c|c|c|c|c|c|c|c|}
\hline \multirow[t]{2}{*}{ Variables } & \multicolumn{2}{|c|}{ Univariate analysis } & \multicolumn{2}{|c|}{$\begin{array}{l}\text { Multivariate analysis based on } \\
\text { complete cases }(\boldsymbol{N}=136)\end{array}$} & \multicolumn{2}{|c|}{$\begin{array}{l}\text { Multivariate analysis based on } \\
\text { imputed datasets }(\boldsymbol{N}=152)\end{array}$} & \multirow[t]{2}{*}{ Points } \\
\hline & $\mathrm{HR}(95 \% \mathrm{Cl})$ & $P$ & HR $(95 \% \mathrm{Cl})$ & $P$ & HR $(95 \% \mathrm{Cl})$ & $P$ & \\
\hline Syncope & $0.52(0.27-1.02)$ & 0.057 & & & $0.64(0.32-1.27)$ & 0.199 & 10 (No syncope) \\
\hline Pulmonary Hypertension & $2.19(1.19-4.04)$ & 0.011 & & & $1.84(0.98-3.48)$ & 0.060 & 14 \\
\hline Moderate or severe TR & $2.32(1.32-4.06)$ & 0.003 & $2.02(1.07-3.80)$ & 0.029 & $1.50(0.82-2.73)$ & 0.186 & 9 \\
\hline $\mathrm{TSH}>4 \mathrm{mlU} / \mathrm{L}$ & $2.14(1.19-3.87)$ & 0.012 & $1.89(1.03-3.46)$ & 0.040 & $1.47(0.79-2.73)$ & 0.220 & 9 \\
\hline NT-proBNP > 1745 pg/mL & $2.93(1.66-5.17)$ & $<0.001$ & $2.32(1.23-4.38)$ & 0.009 & $2.47(1.35-4.49)$ & 0.003 & 20 \\
\hline CLBBB & $0.66(0.39-1.12)$ & 0.120 & $0.56(0.31-1.01)$ & 0.054 & & & \\
\hline LVEF < =35\% & $1.64(0.87-3.11)$ & 0.130 & & & & & \\
\hline IVB & $1.51(0.81-2.81)$ & 0.196 & & & & & \\
\hline Pulmonary congestion & $2.14(1.19-3.87)$ & 0.012 & & & & & \\
\hline \multicolumn{8}{|l|}{ Cardiothoracic ratio } \\
\hline$<=0.5$ & - & - & & & & & \\
\hline $0.51-0.60$ & $1.72(0.52-5.68)$ & 0.371 & & & & & \\
\hline$>0.61$ & $3.15(0.95-10.46)$ & 0.062 & & & & & \\
\hline
\end{tabular}

CLBBB complete left ventricular bundle branch block, IVB intraventricular block, LVEF left ventricular ejection fraction, NT-proBNP N-terminal pro brain natriuretic protein, $T R$ tricuspid regurgitation, $T S H$ thyroid-stimulating hormone

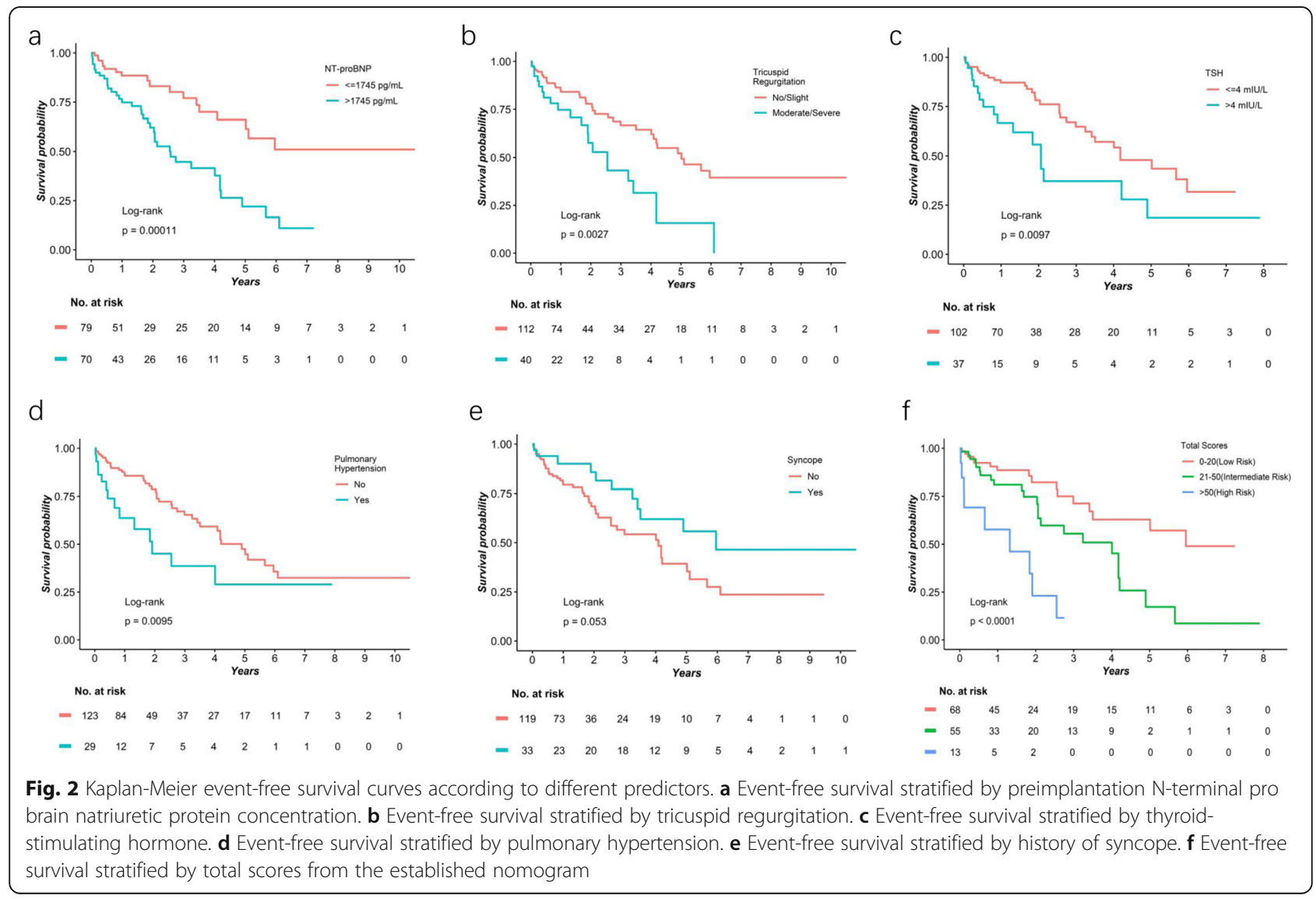




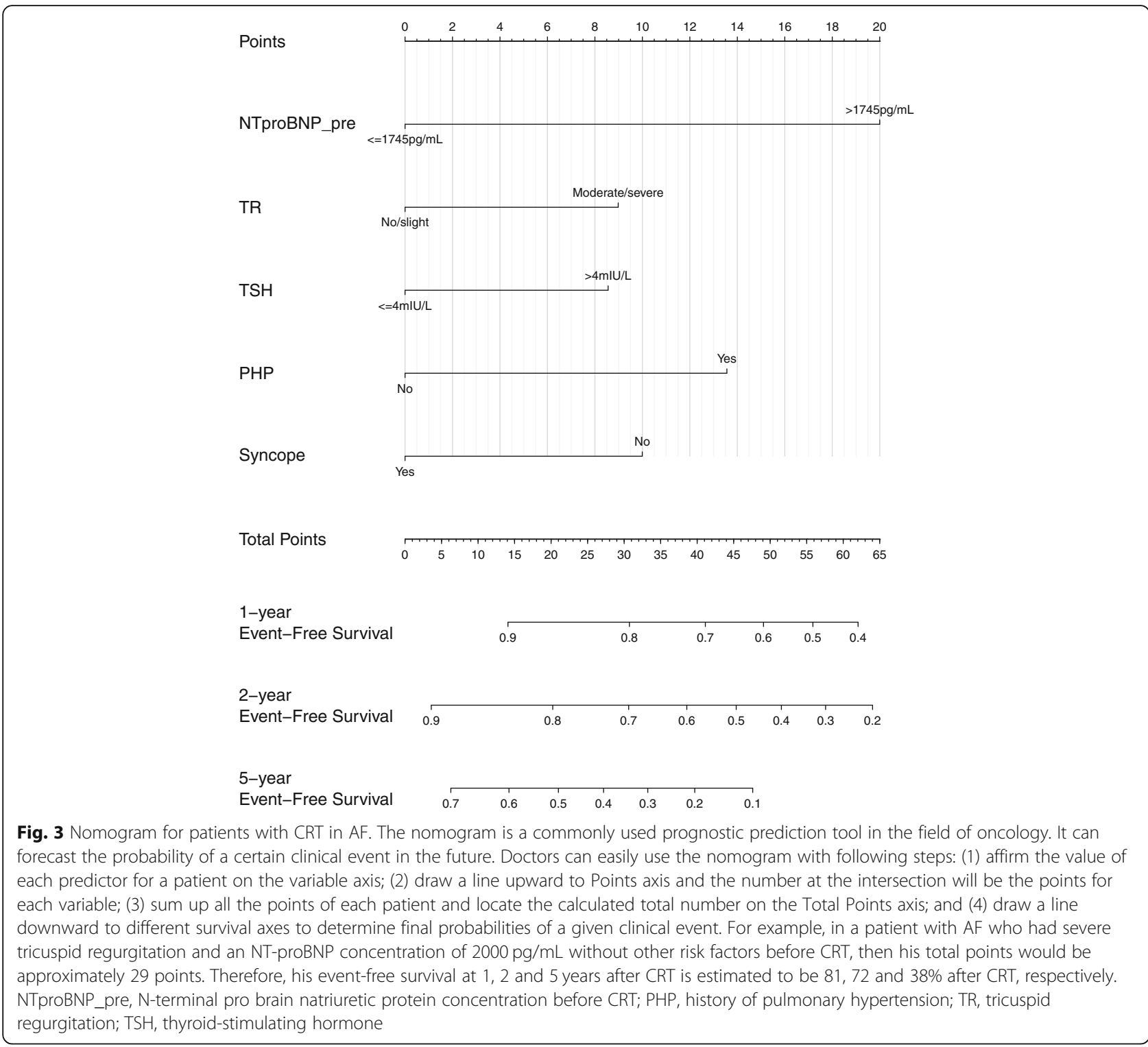

\section{Nomogram versus a single independent predictor}

As shown in Table 2, NT-proBNP > $1745 \mathrm{pg} / \mathrm{mL}$ was an independent risk factor for survival. Therefore, the predictive performance of the established nomogram and NT-proBNP was compared. The C-index for event-free survival prediction was 0.62 (95\% CI, $0.55-0.69)$ by NTproBNP only, significantly lower than the indices of the nomogram $(0.70,95 \%$ CI $0.62-0.77, P=0.0036)$.

\section{Discussion}

The long-term beneficial effects of CRT on overall survival and hospital admissions due to heart failure have been illustrated by previous randomized control trials (RCTs) [2, 3]. However, patients included in RCTs were all in sinus rhythm before CRT implantation, which ignored the fact that AF coincided with HF in $5 \%$ of asymptomatic patients and in nearly $50 \%$ of symptomatic patients [26]. Furthermore, AF worsened the survival probability of patients with HF and was indicated to be an independent risk factor for poor prognosis after CRT [10, 27, 28]. Recent guidelines have given Class IA recommendations to subjects who need ventricular pacing and suffer from a high degree of AVB; AF patients have also been included [1]. However, there is no convenient tool to identify CRT candidates with AF who are at high risk of mortality and heart failure readmissions after implantation. The nomogram we proposed, to the best of our knowledge, is the first easy-to-use predictive model to satisfy this urgent need. Patients with estimations of more than 50 points in our model are predisposed to poor prognosis, so more rational decisions such as AVJA or intensive drug treatment and frequent follow-up should be considered for them. 
a

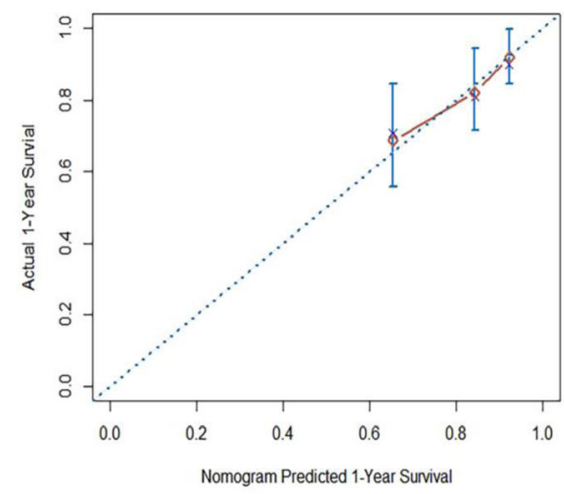

C

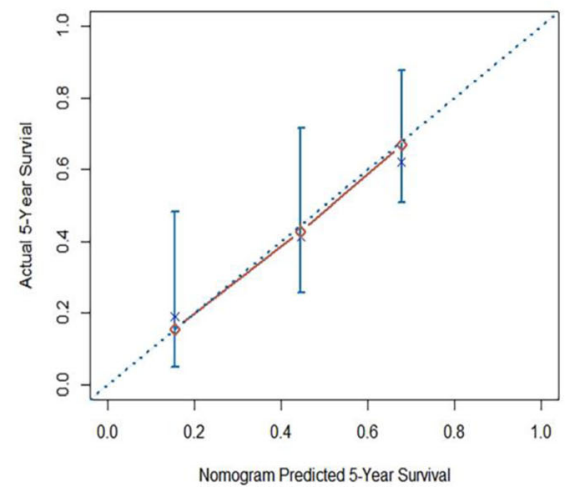

b 2-Year Calibration Curve

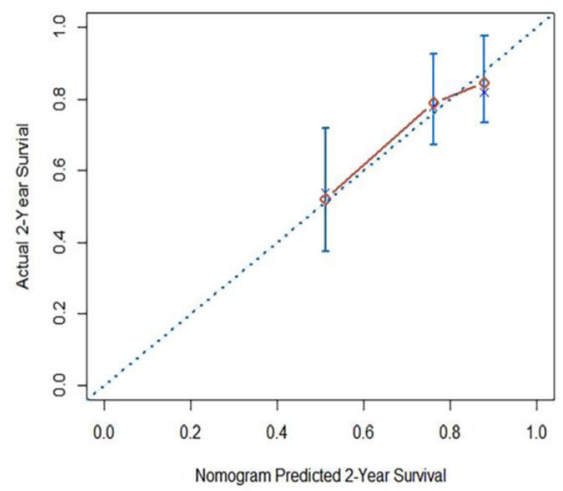

d

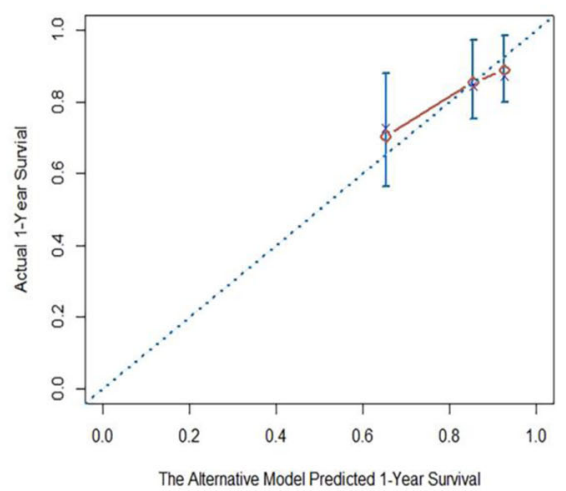

Fig. 4 Calibration curves at different time points. Red lines represent the correlation between actual values and predictive values. Diagonal dashed lines represent the most perfect prediction. The cross signatures represent corrected predictive values versus actual values. a One-year calibration curve. b Two-year calibration curve. c Five-year calibration curve. d One-year calibration curve for the alternative model based on complete cases

Our nomogram included five predictors from conventional examinations and tests before CRT. NTproBNP $>1745 \mathrm{pg} / \mathrm{mL}$ was the only independent risk factor in the multivariate model, where a history of pulmonary hypertension had a marginal significance. Moderate/severe TR, TSH $>4 \mathrm{mIU} / \mathrm{L}$ and history of syncope were not independent predictors. The nomogram established based on this multivariate Cox model showed optimal discrimination (C-index 0.70, 95\% CI 0.62-0.77) and calibration. The corrected Cindex from internal validation also demonstrated fair discrimination $(0.67,95 \%$ CI $0.59-0.74)$.

Additionally, sensitivity analysis based on complete cases confirmed the predictive value of moderate/severe TR, TSH $>4 \mathrm{mIU} / \mathrm{L}$ and NT-proBNP $>1745 \mathrm{pg} / \mathrm{mL}$, which was in accordance with previous findings [17, 19, $21,22,29]$. Notably, increased TSH levels are indicative of overt and subclinical hypothyroidism, which are related to a higher risk of impaired endothelial function and cardiac systolic and diastolic dysfunction posing negative impacts on general prognosis [30]. Experimental evidence also implied that hypothyroidism could increase AF susceptibility in rats due to a longer atrial effective refractory period and left atrial fibrosis associated with thyroid dysfunction [31]. Although history of pulmonary hypertension was not included in the new model, its independent risk on the composite endpoint was reported in patients with CRT $[18,20]$. Thus, it was reasonable as a predictor in the nomogram. Similarly for history of syncope, patients with syncope from arrhythmias or low perfusion were believed to benefit from CRT, explaining its eligibility in the nomogram [1]. Moreover, the new model had inferior agreement between the actual and predicted survival rates compared with the model from imputed datasets. When compared with the univariate model including NT-proBNP, the model from imputed datasets showed significantly better predictive accuracy. Therefore, our nomogram was developed on the model from imputed datasets, and the nomogram-derived scoring system successfully performed risk stratification for patients with distinct long-term event-free survival. 
Interestingly, the type of AF was not associated with the prediction of composite endpoint of HF patients, possibly due to benefits from optimal drug treatments after discharge and a high percentage of biventricular pacing (BIVP, median $>=98 \%$ ), which was consistent with previous conclusions [15, 32]. Even though much data have recommended AVJA for patients undergoing CRT in persistent or permanent AF to ensure better BIVP and prognosis, few studies have explored the effects of paroxysmal AF on long-term prognosis [11]. One study indicated that paroxysmal AF increased the risk of mortality by $32 \%$ after adjustment for age, sex, BIVP\% and shock treatment of CRT-D compared with 51 and $28 \%$ in persistent and permanent AF, respectively [32]. Therefore, AF types may possibly vary in episode duration by definition, but they are supposed to be equally assessed in patients with CRT because clinical diagnosis of AF subtypes was reported to lack accuracy in reflecting AF temporal persistence [33]. Our nomogram implied that various AF subtypes of patients may be regarded evenly in the prediction.

In addition, some previously accepted outcome predictors in CRT recipients were not valid in our nomogram, including CLBBB, QRS duration, ischemic or nonischemic cardiomyopathy, renal dysfunction and MR [1, 10]. This discrepancy may be explained by the following reasons. (1) Predictors such as QRS duration and CLBBB are potentially related to the prognosis of patients in sinus rhythm rather than AF according to current guidelines $[1,14]$. Because all patients of our study were in $\mathrm{AF}$, it seems plausible to obtain different results. Even for CRT candidates in sinus rhythm, they were also reported as lacking predictive accuracy for mortality and HFH [34]. (2) The conception of ischemic or nonischemic cardiomyopathy has been historically used interchangeably with a spectrum of diseases, so we did not consider them as potential predictors in univariate analysis but instead used similar and more specific diagnoses (e.g., coronary heart disease and DCM) [14]. (3) Our retrospective study with a limited population may account for this phenomenon, and the results should be interpreted with caution, although a predictive model derived and validated in large prospective cohorts did not include most of these variables either [35].

Our study has several limitations. First, this is a singlecenter retrospective study with a small sample size. Nonetheless, our center is the largest tertiary hospital of cardiovascular diseases in China, and patients coming from other provinces receive CRT implantation here, which to some extent, augments the extrapolation of our nomogram. Second, the therapeutic effects were not considered in our analysis because regular investigation of daily drug treatment for patients is not practical in our single center. Additionally, during the long study period from 2009 to 2019, indications for CRT, implantation techniques and examination technology have been updated, so the baseline of our patients may not be totally standardized. A limited inclusion timeframe would be favored in future studies on this topic. Finally, our nomogram has not been validated by external cohorts. Therefore, more studies need to be performed to test the validity of our established nomogram.

\section{Conclusion}

In summary, we constructed an easy-to-use and internally validated nomogram containing 5 baseline predictors before CRT. This nomogram allows physicians to evaluate and predict outcomes of CRT recipients in AF and identify subjects with high risk to achieve better prognosis. This nomogram should be applied and validated in external cohorts with larger sample sizes.

\section{Supplementary information}

Supplementary information accompanies this paper at https://doi.org/10. 1186/s12872-020-01502-4.

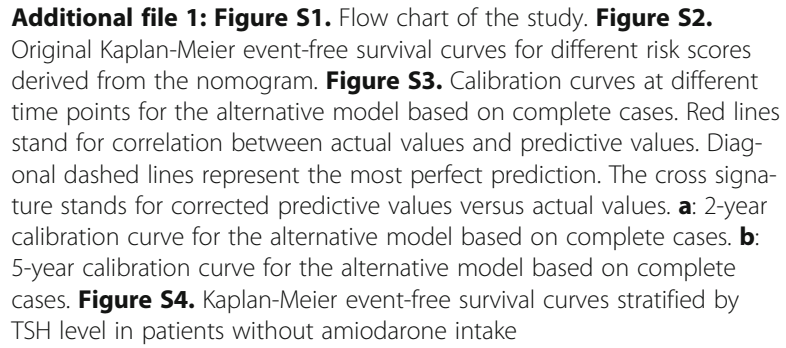

\section{Abbreviations}

ACEl/ARB: Angiotensin-converting enzyme inhibitor/angiotensin II receptor blocker; AF: Atrial fibrillation; AVB: Atrioventricular block; BIVP: Biventricular pacing; BUN: Blood uretic nitrogen; CRT/CRT-D: Cardiac resynchronization therapy/cardiac resynchronization therapy with defibrillator; CABG: Coronary artery bypass grafting; CLBBB: Complete left bundle branch block;

DCM: Dilated cardiomyopathy; eGFR: estimated glomerular filtration rate; EF: Ejection fraction; fPVC: frequent premature ventricular contraction; HF/ $\mathrm{HFH}$ : Heart failure/hospitalization due to heart failure; ICD: Intracardiac defibrillator; IVB: Intraventricular block; LV: Left ventricle; LVEDD: Left ventricular end diastolic diameter; MR: Mitral regurgitation; NYHA: New York heart association; NOAC: Non-vitamin K antagonist oral anticoagulants; NTproBNP: N-terminal pro brain natriuretic protein; PM: Pacemaker; PCl: Percutaneous coronary intervention; QRSd: QRS duration; TR: Tricuspid regurgitation; TSH: Thyroid stimulating hormone; VT: Ventricular tachycardia; VF: Ventricular fibrillation

\section{Acknowledgements}

We thank Professor Frank Harrell for his input on modeling and performance evaluation with multiple imputation.

\section{Authors' contributions}

MC, WH, SY contributed to the study design, data interpretation and writingreview and editing. $M C$ analyzed the data. $\mathrm{WH}, \mathrm{YH}, \mathrm{MG}, \mathrm{HN}, \mathrm{SZ}, \mathrm{SY}, \mathrm{NZ}, \mathrm{MC}$ participated in the study conduction and CRT/CRTD implantation. MC, NZ, YH, HN performed data collection and follow-up. SZ supervised the study. All authors have read and approved the manuscript 


\section{Funding}

This work was supported by the Chinese Academy of Medical Sciences Innovation Fund for Medical Sciences (2017-12M-1-009) and the National Natural Science Foundation of China (81570370). The funding bodies had no role in the research design, data collection, analysis, interpretation, manuscript writing and submission.

\section{Availability of data and materials}

The datasets used and/or analysed during the current study are available from the corresponding author on reasonable request.

\section{Ethics approval and consent to participate}

Written informed consent was obtained before CRT from all patients and the study has been approved by the ethic committee of Fuwai Hospital adhering to the Declaration of Helsinki.

\section{Consent for publication}

Not applicable.

\section{Competing interests}

The authors declare that they have no competing interests.

Received: 23 January 2020 Accepted: 30 April 2020

Published online: 13 May 2020

\section{References}

1. Ponikowski P, Voors AA, Anker SD, Bueno H, Cleland JGF, Coats AJS, Falk V Gonzalez-Juanatey JR, Harjola VP, Jankowska EA, et al. 2016 ESC guidelines for the diagnosis and treatment of acute and chronic heart failure: the task force for the diagnosis and treatment of acute and chronic heart failure of the European Society of Cardiology (ESC) developed with the special contribution of the heart failure association (HFA) of the ESC. Eur Heart J. 2016;37(27):2129-200.

2. Bristow MR, Saxon LA, Boehmer J, Krueger S, Kass DA, De Marco T, Carson P, DiCarlo L, DeMets D, White BG, et al. Cardiac-resynchronization therapy with or without an implantable defibrillator in advanced chronic heart failure. $\mathrm{N}$ Engl J Med. 2004;350(21):2140-50.

3. Cleland JG, Daubert JC, Erdmann E, Freemantle N, Gras D, Kappenberger L, Tavazzi L. Cardiac resynchronization-heart failure study I: the effect of cardiac resynchronization on morbidity and mortality in heart failure. N Engl J Med. 2005;352(15):1539-49.

4. Maisel WH, Stevenson LW. Atrial fibrillation in heart failure: epidemiology, pathophysiology, and rationale for therapy. Am J Cardiol. 2003;91(6):2-8.

5. Tolosana JM, Hernandez Madrid A, Brugada J, Sitges M, Garcia Bolao I, Fernandez Lozano I, Martinez Ferrer J, Quesada A, Macias A, Marin W, et al. Comparison of benefits and mortality in cardiac resynchronization therapy in patients with atrial fibrillation versus patients in sinus rhythm (results of the Spanish atrial fibrillation and resynchronization [SPARE] study). Am J Cardiol. 2008;102(4):444-9.

6. Gasparini M, Leclerca C, Lunati M, Landolina M, Auricchio A, Santini M, Boriani G, Lamp B, Proclemer A, Curnis A, et al. Cardiac resynchronization therapy in patients with atrial fibrillation. JACC Heart Fail. 2013;1 (6):500-7.

7. Linde C, Leclerca C, Rex S, Garrigue S, Lavergne T, Cazeau S, McKenna W, Fitzgerald M, Deharo J-C, Alonso C, et al. Long-term benefits of biventricular pacing in congestive heart failure: results from the MUltisite STimulation in cardiomyopathy (MUSTIC) study. J Am Coll Cardiol. 2002;40(1):111-8.

8. Khadjooi K, Foley PW, Chalil S, Anthony J, Smith RE, Frenneaux MP, Leyva F. Long-term effects of cardiac resynchronisation therapy in patients with atrial fibrillation. Heart. 2008;94(7):879-83.

9. Tolosana JM, Arnau AM, Madrid AH, Macias A, Lozano IF, Osca J, Quesada A, Toquero J, Frances RM, Bolao IG, et al. Cardiac resynchronization therapy in patients with permanent atrial fibrillation. Is it mandatory to ablate the atrioventricular junction to obtain a good response? Eur J Heart Fail. 2012;14(6):635-41.

10. van Bommel RJ, Borleffs CJ, Ypenburg C, Marsan NA, Delgado V, Bertini M, van der Wall EE, Schalij MJ, Bax JJ. Morbidity and mortality in heart failure patients treated with cardiac resynchronization therapy: influence of pre-implantation characteristics on long-term outcome. Eur Heart J. 2010;31(22):2783-90.

11. Mustafa U, Atkins J, Mina G, Dawson D, Vanchiere C, Duddyala N, Jones R, Reddy $P$, Dominic $P$. Outcomes of cardiac resynchronisation therapy in patients with heart failure with atrial fibrillation: a systematic review and meta-analysis of observational studies. Open Heart. 2019;6(1):e000937.
12. Kirchhof P, Benussi S, Kotecha D, Ahlsson A, Atar D, Casadei B, Castella M, Diener HC, Heidbuchel H, Hendriks J, et al. 2016 ESC guidelines for the management of atrial fibrillation developed in collaboration with EACTS. Eur Heart J. 2016:37(38):2893-962.

13. Hunt SA, Abraham WT, Chin MH, Feldman AM, Francis GS, Ganiats TG, Jessup M, Konstam MA, Mancini DM, Michl K, et al. ACC/AHA 2005 Guideline Update for the Diagnosis and Management of Chronic Heart Failure in the Adult: a report of the American College of Cardiology/ American Heart Association Task Force on Practice Guidelines (Writing Committee to Update the 2001 Guidelines for the Evaluation and Management of Heart Failure): developed in collaboration with the American College of Chest Physicians and the International Society for Heart and Lung Transplantation: endorsed by the Heart Rhythm Society. Circulation. 2005;112(12):e154-235.

14. Writing Committee M, Yancy CW, Jessup M, Bozkurt B, Butler J, Casey DE Jr, Drazner MH, Fonarow GC, Geraci SA, Horwich T, et al. 2013 ACCF/AHA guideline for the management of heart failure: a report of the American College of Cardiology Foundation/American Heart Association task force on practice guidelines. Circulation. 2013;128(16):e240-327.

15. Koplan BA, Kaplan AJ, Weiner S, Jones PW, Seth M, Christman SA. Heart failure decompensation and all-cause mortality in relation to percent biventricular pacing in patients with heart failure: is a goal of $100 \%$ biventricular pacing necessary? J Am Coll Cardiol. 2009;53(4):355-60.

16. Zhang $S$, Singh B, Rodriguez DA, Chasnoits AR, Hussin A, Ching CK, Huang $D$, Liu YB, Cerkvenik J, Willey S, et al. Improve the prevention of sudden cardiac arrest in emerging countries: the improve SCA clinical study design. Europace. 2015;17(11):1720-6.

17. Smit MD, Maass AH, Hillege HL, Wiesfeld AC, Van Veldhuisen DJ, Van Gelder IC. Prognostic importance of natriuretic peptides and atrial fibrillation in patients receiving cardiac resynchronization therapy. Eur J Heart Fail. 2011;13(5):543-50.

18. Stern J, Heist EK, Murray L, Alabiad C, Chung J, Picard MH, Semigran MJ, Ruskin JN, Singh JP. Elevated estimated pulmonary artery systolic pressure is associated with an adverse clinical outcome in patients receiving cardiac resynchronization therapy. Pacing Clin Electrophysiol. 2007;30(5):603-7.

19. Berger R, Shankar A, Fruhwald F, Fahrleitner-Pammer A, Freemantle N, Tavazzi L, Cleland JG, Pacher R. Relationships between cardiac resynchronization therapy and $\mathrm{N}$-terminal pro-brain natriuretic peptide in patients with heart failure and markers of cardiac dyssynchrony: an analysis from the cardiac resynchronization in heart failure (CARE-HF) study. Eur Heart J. 2009;30(17):2109-16.

20. Chatterjee NA, Upadhyay GA, Singal G, Parks KA, Dec GW, Singh JP, Lewis GD. Pre-capillary pulmonary hypertension and right ventricular dilation predict clinical outcome in cardiac resynchronization therapy. JACC Heart Fail. 2014;2(3):230-7.

21. Grupper A, Killu AM, Friedman PA, Abu Sham'a R, Buber J, Kuperstein R, Rozen G, Asirvatham SJ, Espinosa RE, Luria D, et al. Effects of tricuspid valve regurgitation on outcome in patients with cardiac resynchronization therapy. Am J Cardiol. 2015;115(6):783-9.

22. Sharma AK, Vegh E, Orencole M, Miller A, Blendea D, Moore S, Lewis GD, Singh JP, Parks KA, Heist EK. Association of hypothyroidism with adverse events in patients with heart failure receiving cardiac resynchronization therapy. Am J Cardiol. 2015;115(9):1249-53.

23. Lausen B, Schumacher M. Maximally selected rank statistics. Biometrics. 1992;48(1):73-85.

24. Wood AM, White IR, Royston P. How should variable selection be performed with multiply imputed data? Stat Med. 2008;27(17):3227-46.

25. Alba AC, Agoritsas T, Walsh M, Hanna S, lorio A, Devereaux PJ, McGinn T, Guyatt G. Discrimination and calibration of clinical prediction models: Users' guides to the medical literature. JAMA. 2017;318(14):1377-84.

26. Gasparini M, Galimberti P. Atrial fibrillation and cardiac resynchronization therapy. Curr Opin Cardiol. 2018;33(1):1-6.

27. Dries D, Exner D, Gersh B, Domanski M, Waclawiw M, Stevenson L. Atrial fibrillation is associated with an increased risk for mortality and heart failure progression in patients with asymptomatic and symptomatic left ventricular systolic dysfunction: a retrospective analysis of the SOLVD trials. J Am Coll Cardiol. 1998;32(3):695-703.

28. Mathew J, Hunsberger S, Fleg J, Mc Sherry F, Williford W, Yusuf S. Incidence, predictive factors, and prognostic significance of supraventricular tachyarrhythmias in congestive heart failure. Chest. 2000;118(4):914-22.

29. Kristensen SL, Jhund PS, Mogensen UM, Rorth R, Abraham WT, Desai A, Dickstein K, Rouleau JL, Zile MR, Swedberg K, et al. Prognostic value of N- 
Terminal Pro-B-Type Natriuretic Peptide levels in heart failure patients with and without atrial fibrillation. Circ Heart Fail. 2017;10(10):e004409.

30. Biondi B, Klein I. Hypothyroidism as a risk factor for cardiovascular disease. Endocrine. 2004;24(1):001-14.

31. Zhang Y, Dedkov El, Teplitsky D, Weltman NY, Pol CJ, Rajagopalan V, Lee B, Gerdes AM. Both hypothyroidism and hyperthyroidism increase atrial fibrillation inducibility in rats. Circ Arrhythm Electrophysiol. 2013;6(5):952-9.

32. Ousdigian KT, Borek PP, Koehler JL, Heywood JT, Ziegler PD, Wilkoff BL. The epidemic of inadequate biventricular pacing in patients with persistent or permanent atrial fibrillation and its association with mortality. Circ Arrhythm Electrophysiol. 2014;7(3):370-6

33. Charitos El, Purerfellner H, Glotzer TV, Ziegler PD. Clinical classifications of atrial fibrillation poorly reflect its temporal persistence: insights from 1,195 patients continuously monitored with implantable devices. J Am Coll Cardiol. 2014;63(25 Pt A):2840-8.

34. Kalscheur MM, Kipp RT, Tattersall MC, Mei C, Buhr KA, DeMets DL, Field ME, Eckhardt LL, Page CD. Machine learning algorithm predicts cardiac resynchronization therapy outcomes: lessons from the COMPANION trial. Circ Arrhythm Electrophysiol. 2018;11(1):e005499.

35. Levy WC, Mozaffarian D, Linker DT, Sutradhar SC, Anker SD, Cropp AB, Anand I, Maggioni A, Burton P, Sullivan MD, et al. The Seattle heart failure model: prediction of survival in heart failure. Circulation. 2006;1 13(11):1424-33.

\section{Publisher's Note}

Springer Nature remains neutral with regard to jurisdictional claims in published maps and institutional affiliations.

Ready to submit your research? Choose BMC and benefit from:

- fast, convenient online submission

- thorough peer review by experienced researchers in your field

- rapid publication on acceptance

- support for research data, including large and complex data types

- gold Open Access which fosters wider collaboration and increased citations

- maximum visibility for your research: over $100 \mathrm{M}$ website views per year

At $\mathrm{BMC}$, research is always in progress.

Learn more biomedcentral.com/submissions 